\title{
Evidence for a hyper-reductive redox in a sub-set of heart failure patients
}

\author{
Thiagarajan Sairam², Amit N. Patel ${ }^{3}$, Meenu Subrahmanian², Rajendiran Gopalan, Steven M. Pogwizd5, \\ Sudha Ramalingam ${ }^{2}$, Ramalingam Sankaran ${ }^{2^{*}}$ and Namakkal Soorapan Rajasekaran ${ }^{1,2,6^{*}}$
}

\begin{abstract}
Background: Oxidative stress has been linked to heart failure (HF) in humans. Antioxidant-based treatments are often ineffective. Therefore, we hypothesize that some of the HF patients might have a reductive stress (RS) condition. Investigating RS-related mechanisms will aid in personalized optimization of redox homeostasis for better outcomes among HF patients.

Methods: Blood samples were collected from HF patients $(n=54)$ and healthy controls $(n=42)$ and serum was immediately preserved in $-80^{\circ} \mathrm{C}$ for redox analysis. Malondialdehyde (MDA; lipid peroxidation) levels by HPLC, reduced glutathione (GSH) and its redox ratio (GSH/GSSG) using enzymatic-recycling assay in the serum of HF patients were measured. Further, the activities of key antioxidant enzymes were analyzed by UV-Vis spectrophotometry. Non-invasive echocardiography was used to relate circulating redox status with cardiac function and remodeling.

Results: The circulatory redox state (GSH/MDA ratio) was used to stratify the HF patients into normal redox (NR), hyper-oxidative $(\mathrm{HO})$, and hyper-reductive (HR) groups. While the majority of the HF patients exhibited the HO (42\%), $41 \%$ of them had a normal redox (NR) state. Surprisingly, a subset of HF patients (17\%) belonged to the hyper-reductive group, suggesting a strong implication for RS in the progression of HF. In all the groups of HF patients, SOD, GPx and catalase were significantly increased while GR activity was significantly reduced relative to healthy controls. Furthermore, echocardiography analyses revealed that $55 \%$ of $\mathrm{HO}$ patients had higher systolic dysfunction while $62.5 \%$ of the hyper-reductive patients had higher diastolic dysfunction.
\end{abstract}

Conclusion: These results suggest that RS may be associated with HF pathogenesis for a subset of cardiac patients. Thus, stratification of HF patients based on their circulating redox status may serve as a useful prognostic tool to guide clinicians designing personalized antioxidant therapies.

Keywords: Hyper-reductive, Hyper-oxidative, Heart failure, Circulatory redox state, Reductive stress

\section{Background}

There is a general consensus that oxidative stress induces various pathophysiological processes including cardiovascular complications [1, 2]; however, counteracting antioxidant supplementations have failed to prevent the

\footnotetext{
*Correspondence: drrampsg@gmail.com; rajnsr@uabmc.edu

${ }_{1}^{1}$ Cardiac Aging \& Redox Signaling Laboratory, Center for Free Radical Biology, Division of Molecular \& Cellular Pathology, Department of Pathology, UAB|The University of Alabama at Birmingham, BMR2 Room 533|901 19th Street South, Birmingham, AL 35294-2180, USA

2 PSG Center for Molecular Medicine and Therapeutics, PSG Institute of Medical Sciences \& Research (Affiliated to the Tamilnadu Dr MGR Medical University), Coimbatore, Tamil Nadu, India

Full list of author information is available at the end of the article
}

progression or curtail disease pathogenesis [3, 4]. At present, it is not clear whether oxidative stress is a cause or consequence in a given cell or organ system exhibiting a chronic disease state. Therefore, it is vital to critically analyze the global redox milieu of patients experiencing chronic illnesses including heart failure (HF). HF is a progressive condition in which the cardiac muscle weakens and becomes inefficient to meet the body's demand for blood and oxygen supply. The etiology of HF is multifaceted as several genetic, biochemical, electrical and inflammatory factors have been shown to underlie the structural and functional remodeling that develops over time [5-8]. Based on the currently available literature, a majority of 
the HF conditions have been correlated with oxidative stress for the past several decades. In particular, ischemic heart disease and/or reperfusion injury have been shown to display a hyper-oxidative state wherein increased reactive oxygen and nitrogen species (ROS/RNS) generation correlates with a worsening of myocardial injury [9-11]. In spite of these observations, supplementation with antioxidants seems to be inefficient to treat such conditions in a failing heart [12-14]. In particular, pre-clinical observations using rodent models have documented that a forced induction of oxidative stress leads to "heart failure" and pre-treatment with potential antioxidants seems to be protective [15-17]. However, these findings were not reproducible in HF patients [18-20].

To the best of our knowledge, all HF studies have focused on documenting the differences between HF patients and healthy control groups, and have not examined the potential for individual variations in the context of redox status among HF patients. Importantly, findings based on a group may not be precise to each individual of that group. Therefore, considering the inconsistent effects of antioxidant trials in human patients, it is worth testing whether all HF patients experience similar redox state. The ROS/RNS produced during basal mitochondrial metabolism (oxygen consumption at resting state) or in response to physical activity are key modulators of cellular motility to maintain a redox homeostasis and preserve the dynamic function of the myocardium [2124]. However, other factors including genetic or chronic stresses that modulate ROS/RNS may tip the redox milieu towards either direction of the redox spectrum (i.e. reductive or oxidative). Despite several studies demonstrating the futility and/or detrimental effects of antioxidants, there has not been a single study attempting to understand the mechanisms associated with failure of the antioxidants in over six decades of biomedical research. In the present study, we attempt to address this critical gap in knowledge and postulate that some HF patients may either exhibit a hyper-reductive or normal redox state potentially conferring vulnerability and inimical side effects to antioxidant treatment.

In the current study, we determined the circulatory redox state of HF patients by measuring glutathione redox (GSH:GSSG) ratio, lipid peroxidation (MDA) and the activities of key antioxidant enzymes to compare with the healthy control group. Moreover, we utilized the ratio of GSH/MDA as a peripheral redox index and focused on stratifying HF patients according to this measure. Our findings revealed a surprising but meaningful observation in that there appears to be distinct subsets of HF patients exhibiting divergent redox signatures. Therefore, our data indicates that not all HF patients have oxidative stress as traditionally reported. Our pilot observations in this small cohort of HF patients $(n=54)$ warrant a new redox-based classification in these patients for selecting an appropriate therapy.

\section{Methods \\ Study population}

Our study population included heart failure (HF) patients $(\mathrm{n}=54)$ (with systolic or diastolic dysfunction, dilated cardiomyopathy or biventricular dysfunction) and healthy controls $(n=42)$ who attended the in-patient and out-patient department of cardiology in PSG Hospitals, Tamil Nadu, India. Their characteristics are tabulated in Table 1. Patients with HF who were diagnosed using Framingham criteria were considered for this study [25]. Patients on dialysis, as well as those exhibiting severe liver diseases, malignancies or consuming antioxidant supplements were excluded from the study. While $85 \%$ of patients were admitted to the hospital for the first time, the remaining were presented for follow-up visits. The patients were treated as per the existing guidelines at the time. Briefly, the patients were categorized into those displaying heart failure (HF) with reduced ejection fraction (HFrEF) and preserved ejection fraction (HFpEF). The patients with HFrEF received stage-appropriate medications such as ACE inhibitors or Beta Blockers or ARBS alone or in combination, along with diuretics. Mineralocorticoid Receptor Antagonists and Hydralazine were also added if required. Patients with HRpEF had diuretics as their main stay along with the treatment of underlying causes such as coronary artery disease, chronic kidney disease, HF, atrial fibrillation etc. The study was approved by the PSG Institutional Human Ethics Committee (IHEC) and all patients/subjects completed a written informed consent prior to their participation.

\section{Reagents}

Supplies and reagents were purchased from Sisco Research Laboratories (India) unless otherwise specified.

\section{Clinical assessment and echocardiography}

Validation and confirmation of HF in patients were made based on clinical and echocardiography assessment. One echocardiogram was selected for each patient at the time of enrollment. Two-dimensional and M-mode echocardiography, color flow and spectral Doppler as well as annular TDI data were obtained from all patients and healthy controls using an ultrasound system (Philips IE33, Netherlands). Standard views, including the parasternal long axis view, short axis at the papillary muscle level and apical four and two chamber views were recorded. Cardiac chamber dimensions, volumes and left ventricular mass were measured according to current recommendations [26]. Left ventricular ejection fraction (LV EF) was 
Table 1 Demographic details for heart failure patients and healthy controls

\begin{tabular}{|c|c|c|c|c|}
\hline \multirow[t]{2}{*}{ Characteristics of patients } & \multicolumn{3}{|c|}{ Heart failure patients $(n=54)$} & \multirow[t]{2}{*}{ Healthy controls } \\
\hline & $\begin{array}{l}\text { Hyperreductive } \\
(n=9)\end{array}$ & $\begin{array}{l}\text { Hyperoxidative } \\
(n=23)\end{array}$ & $\begin{array}{l}\text { Normal redox } \\
(n=22)\end{array}$ & \\
\hline Age in years: mean age $(\text { range })^{\dagger}$ & $50(32-75)$ & $58(34-73)$ & $52(34-75)$ & $36.35(18-64)$ \\
\hline Sex: $\mathrm{n}(\% \text { male })^{+}$ & $9(100)$ & $23(100)$ & $21(95)$ & $27(64)$ \\
\hline Mean height in $\mathrm{cm}(\text { range })^{\dagger}$ & $164(151.7-177)$ & $163(152-173)$ & $163(143-178)$ & $165.8(148-192)$ \\
\hline Mean weight in $\mathrm{kg}(\text { range })^{\dagger}$ & $60(50-70)$ & $62(41-75)$ & $63(38-100)$ & $62.7(38-89)$ \\
\hline Body mass index $\left(\mathrm{kg} / \mathrm{m}^{2}\right)(\text { range })^{\dagger}$ & $22(19.5-24.5)$ & $23(16.4-30.3)$ & $24(15.2-35.4)$ & $22.9(16.1-34.6)$ \\
\hline \multicolumn{5}{|l|}{ Hemodynamics $^{\dagger}$} \\
\hline Heart rate (no. of times/min) & $97(60-100)$ & $94(74-121)$ & $96(70-116)$ & $78(64-98)$ \\
\hline Mean systolic blood pressure (mmHg) & $129(80-170)$ & $129(80-180)$ & $125(90-170)$ & $119(90-190)$ \\
\hline Mean diastolic blood pressure $(\mathrm{mmHg})$ & $79(60-140)$ & $85(60-110)$ & $77(50-110)$ & $76(50-110)$ \\
\hline \multicolumn{5}{|l|}{ Comorbidities, $\%^{\dagger}$} \\
\hline DM and DM associated disorders & $5(55)$ & $15(65)$ & $10(45)$ & - \\
\hline Systemic hypertension & $3(33)$ & $5(22)$ & $6(27)$ & - \\
\hline Hypothyroidism & 0 & $4(17)$ & $1(4.5)$ & - \\
\hline Chronic kidney disease & $1(11)$ & $3(13)$ & 0 & - \\
\hline Anaemia & 0 & $2(7)$ & $2(9)$ & - \\
\hline BPH (benign prostatic hyperplasia) & $1(11)$ & 0 & $1(4.5)$ & - \\
\hline Hepatitis & 0 & 0 & $1(4.5)$ & - \\
\hline CVA (cerebrovascular accident) & 0 & $1(4)$ & 0 & - \\
\hline COPD & $1(11)$ & $2(9)$ & $3(14)$ & - \\
\hline \multicolumn{5}{|l|}{ Cardiac disease pathology, $\%^{\dagger}$} \\
\hline Dilated cardiomyopathy & $5(55)$ & $8(35)$ & $9(41)$ & - \\
\hline Coronary artery disease & $2(22)$ & $10(43)$ & $10(45)$ & - \\
\hline Rheumatic heart disease & $1(11)$ & 0 & $2(9)$ & - \\
\hline Ischemic heart disease & 0 & $1(4)$ & $1(4.5)$ & - \\
\hline Aortoiliac disease & $1(11)$ & $5(22)$ & 0 & - \\
\hline Diastolic dysfunction & $10(43)$ & $7(32)$ & $8(89)$ & - \\
\hline Systolic dysfunction & $16(69.5)$ & $19(86)$ & $9(100)$ & - \\
\hline Biventricular dysfunction & $6(26)$ & $4(18)$ & 0 & - \\
\hline Pulmonary artery hypertension (PAH) & $12(52)$ & $10(45)$ & $4(44)$ & - \\
\hline \multicolumn{5}{|l|}{ Medication, \%* } \\
\hline Diuretics & $5(55)$ & $20(87)$ & $18(82)$ & - \\
\hline$\beta$ blockers & $4(44)$ & $12(52)$ & $12(54)$ & - \\
\hline Statins & $1(11)$ & $9(39)$ & $6(27)$ & - \\
\hline ACE inhibitors & $3(33)$ & $10(43)$ & $10(45)$ & - \\
\hline Digitalis glycosides & $3(33)$ & $11(48)$ & $4(18)$ & - \\
\hline Anticoagulant & $1(11)$ & $5(22)$ & $2(9)$ & - \\
\hline (ARB) angiotensin II antagonists & 0 & $5(22)$ & $1(4.5)$ & - \\
\hline Antiplatelet medications & 0 & $5(22)$ & $3(14)$ & - \\
\hline
\end{tabular}

${ }^{*} p=0.005$, statistically significant

$+\mathrm{p}=\mathrm{ns}$, nonsignificant

calculated using the teichholz formula [27]. Mitral Doppler signals were recorded in apical 4 chamber view, with Doppler sample volume placed at the tip of the mitral valve leaflets. The following parameters were obtained: early diastolic mitral inflow peak velocity (E), late diastolic mitral inflow peak velocity (A) and their ratio.

\section{Blood sampling}

Blood samples were obtained by venipuncture using a 21 -gauge needle from the patients and healthy control subjects in plain tubes. Serum was separated by centrifugation at $3000 \mathrm{rpm}$ for $5 \mathrm{~min}$ at $4{ }^{\circ} \mathrm{C}$ and immediately aliquoted and frozen at $-80^{\circ} \mathrm{C}$. A fraction of the serum was 
treated with $10 \%$ meta-phosphoric acid (MPA) to remove proteins and the MPA-supernatant was stored for glutathione redox analysis instantly after the blood collection for all the controls and patients. The stored aliquots of serum were used for analyzing redox status and the activities of antioxidant enzymes.

\section{Lipid peroxidation}

Serum malondialdehyde levels were measured by the DNPH (2,4-dinitrophenyl hydrazine) derivatization method [28]. Briefly, $125 \mu \mathrm{l}$ of serum was diluted in $125 \mu \mathrm{l} 1 \times$ PBS (pH 7.4), mixed with $50 \mu \mathrm{l}$ of $6 \mathrm{M} \mathrm{NaOH}$ and incubated at $60{ }^{\circ} \mathrm{C}$ for $30 \mathrm{~min} .125 \mu \mathrm{l}$ of $35 \%$ perchloric acid was then added to the mixture. $250 \mu \mathrm{l}$ of this mixture was combined with $25 \mu \mathrm{l}$ of $5 \mathrm{mM} \mathrm{DNPH}$ (in $2 \mathrm{M} \mathrm{HCl}$ ) and incubated in the dark for $30 \mathrm{~min}$. An aliquot of $25 \mu \mathrm{l}$ of the solution was injected into the HPLC system (Shimadzu, Japan). The mobile phase of $0.2 \%(\mathrm{v} / \mathrm{v})$ acetic acid and acetonitrile $(50: 50 \mathrm{v} / \mathrm{v})$ was run at a flow rate of $0.5 \mathrm{ml} / \mathrm{min}$ at $25^{\circ} \mathrm{C}$. A C18 column (Agilent, USA) was used and the chromatograms were obtained at $310 \mathrm{~nm}$. Concentration of MDA was measured after comparing with a reference curve using TMP (1,1,3,3-tetramethoxypropane) as a standard.

\section{Reduced glutathione levels}

The spectrophotometric based glutathione reductase $/ 5,5^{\prime}$ dithio-bis (2-nitrobenzoic acid) (DTNB) recycling assay was used to measure reduced glutathione (GSH) levels as per [29-31] with minor modifications. In short, metaphosphoric acid extracts of serum samples were prepared and treated with triethanolamine (TEAM reagent) to adjust the $\mathrm{pH}$ for total GSH quantification according to the manufacturers' protocols (GSH redox Kit \#CS0260, Sigma-Aldrich). An aliquot of TEAM treated samples were mixed with $1.0 \mathrm{mM}$ 2-vinyl pyridine and incubated for $1.0 \mathrm{~h}$ at room temperature for GSSG measurements. For enzymatic recycling, the processed samples were treated with a reaction mixture containing $0.25 \mathrm{mM}$ dithiobis-nitrobenzoic acid (DTNB), $0.38 \mathrm{U} / \mathrm{ml}$ Glutathione reductase and $60 \mu \mathrm{l}$ of $0.17 \mathrm{mM}$ NADPH in $0.1 \mathrm{M}$ sodium phosphate buffer ( $\mathrm{pH} 7.4)$ with $5 \mathrm{mM}$ EDTA. The rate of DTNB formation was measured at A412 nm. Similarly, GSH and GSSG standards were treated and measured to obtain a standard graph to extrapolate the values from serum samples. The concentration of reduced glutathione (GSH) was estimated by subtracting the measured oxidized (GSSG) glutathione levels from the measured total (GSH plus GSSG) glutathione. GSH/GSSG ratio was then determined.

\section{Superoxide dismutase (SOD) activity}

Superoxide dismutase activity in the serum samples were measured using the pyrogallal auto-oxidation method
[32]. This assay was carried out in a microtiter plate and the readings were measured using multimode reader (Varioskan Flash, Thermoscientific, USA). Approximately $50 \mu \mathrm{l}$ of serum was treated with $25 \mu \mathrm{l}$ ethanol and $15 \mu \mathrm{l}$ chloroform. The contents were vortexed and centrifuged at $8000 \mathrm{rpm}$ for $5 \mathrm{~min}$ and the supernatant was analyzed for SOD activity by mixing with $50 \mathrm{mM}$ Tris- $\mathrm{HCl}$ buffer with $1.0 \mathrm{mM}$ EDTA, $\mathrm{pH} 8.2$ and $2.0 \mathrm{mM}$ pyrogallal (in $50 \mathrm{mM} \mathrm{HCl})$. The rate of autoxidation was measured from the increase in absorbance at $420 \mathrm{~nm}$ and the values were expressed as $\mathrm{U} / \mathrm{ml}$.

\section{Catalase activity}

The activity of catalase in serum of HF and $\mathrm{HC}$ samples was measured by $\mathrm{H}_{2} \mathrm{O}_{2}$ decomposition kinetics using a spectrophotometer [33]. A mixture containing potassium phosphate buffer (50 mM, pH 7.0), $20 \mathrm{mM} \mathrm{H}_{2} \mathrm{O}_{2}$ and $2.0 \mu \mathrm{l}$ serum was used to measure the rate of decrease in optical density at $240 \mathrm{~nm}$. Catalase activity was expressed as $\mathrm{U} / \mathrm{l}$.

\section{Glutathione reductase activity}

Glutathione reductase activity was assayed by monitoring NADPH oxidation linked to GSSG reduction [34] using a spectrophotometer. The assay was performed by suspending $10 \mu \mathrm{l}$ of the serum in sodium phosphate buffer (0.3 M, pH 6.8), 25 mM EDTA, 20 mM GSSG, $2 \mathrm{mM}$ NADPH and measuring the decrease in absorbance at $340 \mathrm{~nm}$ over time. The oxidation of $1 \mu \mathrm{mol}$ of $\mathrm{NADPH} / \mathrm{min}$ was used as a unit of glutathione reductase activity. Glutathione reductase activity was expressed as U/l.

\section{Glutathione peroxidase activity}

Glutathione peroxidase (GPx) activity was measured by a spectrophotometric assay using 5,5'-dithio-bis (2-nitrobenzoic acid) (DTNB) according to [35] where the oxidation of GSH in the presence of $\mathrm{H}_{2} \mathrm{O}_{2}$ takes place, and the unused GSH reacts with DTNB whose absorbance was measured at $412 \mathrm{~nm}$. The enzyme assay was performed by incubating the serum $(25 \mu \mathrm{l})$ in sodium phosphate buffer containing sodium azide $(10 \mathrm{mM})$, GSH $(4 \mathrm{mM})$ and $2.5 \mathrm{mMH}_{2} \mathrm{O}_{2}$ for 5 min. Protein was precipitated using $10 \%$ trichloroacetic acid, centrifuged at $5000 \mathrm{rpm}$ for $5 \mathrm{~min}$, and the supernatant was assayed. This assay was carried out in a microtitre plate and the readings were measured using multimode reader (Varioskan Flash, Thermoscientific, USA) after mixing with disodium hydrogen phosphate (0.3 M, pH 7.0) and $100 \mathrm{mM}$ DTNB (in $1 \%$ sodium citrate) at $412 \mathrm{~nm}$. GPx activity (U/l) was measured as the amount of GSH consumed/ $\mathrm{min} / \mathrm{mg}$ protein after reaction with GPx and DTNB. 


\section{Protein estimation}

Serum proteins were estimated using Bradford method. A known volume $(5 \mu \mathrm{l})$ of 1:100 diluted serum was incubated in Bradford reagent (\#18004246723, Biorad, USA) and measured the absorbance at $595 \mathrm{~nm}$. The absorbance was extrapolated with the appropriate standard reference curve using bovine serum albumin $(0.031-0.5 \mathrm{mg} / \mathrm{ml})$ and the protein concentration was calculated. Specific activity for the antioxidant enzymes were measured after normalizing with the respective protein concentration.

\section{Statistical analysis}

For comparing two groups, Mann-Whitney U test was used for non-normal data and for groups with normal distribution, group mean \pm standard deviation (SD) were compared, homogeneity variance test (Bartlett's test) followed by one way ANOVA was carried out. A p >0.05 was considered to be statistically significant. Fisher's exact test was performed to analyse statistical significance of EF fraction and E/A ratio among the different groups of HF patients. For data which was not normally distributed, a nonparametric test, Kruskal-Wallis test was carried out to obtain the $\mathrm{p}$ value. All the statistical analyses were carried out using GraphPad Prism software version 5.0 Windows (GraphPad Software, USA).

\section{Results}

\section{Stratification of heart failure patients based on circulatory} redox status

Circulatory redox state (CRS) was assessed by quantifying the levels of reduced glutathione (GSH), a ubiquitous, small molecular antioxidant redox couple and malondialdehyde (MDA), an end-product of lipid peroxidation (Fig. 1). Compared to the healthy controls (HC; $\mathrm{n}=42$ ), circulating GSH levels were unchanged in HF patients $(\mathrm{n}=54)(0.09207 \pm 0.1215 \mu \mathrm{M}$ in $\mathrm{HF}$ patients vs. $0.06374 \pm 0.04887 \mu \mathrm{M}$ in $\mathrm{HC} ; \mathrm{p}=\mathrm{NS}$; Fig. 1a), suggesting a wide range of redox states among the HF patients. In addition to total glutathione levels, the ratio of reduced to oxidized glutathione (GSH:GSSG) did not differ between HF and HC (4.93 \pm 7.25 in HF patients vs. $3.01 \pm 1.78$ in $\mathrm{HC}$; $\mathrm{p}=\mathrm{NS}$; Fig. $1 \mathrm{c})$. In contrast, MDA was significantly higher in $\mathrm{HF}$ patients vs. HC (4.342 \pm 2.103 vs. $1.566 \pm 0.3018 \mu \mathrm{M}$, respectively; $\mathrm{p}<0.0001$ ) (Fig. 1b), suggesting that increased lipid peroxidation is coupled with the development of HF. Therefore, we next assessed whether the redox index (reduction vs. oxidation) is significantly different between the groups. Comparisons of GSH/GSSG ratio revealed insignificant differences between the groups, indicating that the HF patients seem to exhibit a wide range of redox levels in relation to $\mathrm{HC}(4.93 \pm 7.25$ in $\mathrm{HF}$ patients vs. $3.01 \pm 1.78$ in $\mathrm{HC}$; $\mathrm{p}=$ NS; Fig. 1c). Therefore, our approach for stratifying
HF patients used CRS (i.e. GSH/MDA) to gain more knowledge and understand the pathogenesis. But, comparisons of GSH/MDA ratios between the $\mathrm{HF}$ and $\mathrm{HC}$ yielded a statistically significant result $(0.02 \pm 0.0345$ in HF patients vs. $0.04 \pm 0.028$ in $\mathrm{HC}$; $\mathrm{p}<0.0001$; Fig. 1d). Therefore, we were interested in stratifying the HF patients based on their circulating redox score (CRS) (Fig. 1d). The CRS of healthy subjects was designated as normal redox (NR). A CRS value in any patient lower than the NR displayed by $\mathrm{HC}$ was regarded as hyper-oxidative $(\mathrm{HO})$ while a patient exhibiting a GSH/MDA ratio greater than the NR cutoff was classified as hyper-reductive (HR). Surprisingly, our CRS-based stratification revealed three distinct classes within our cohort of HF patients (Fig. 1e). Along these lines, $41 \%$ of HF patients were assigned to the normal redox (NR) group whose mean GSH/MDA ratio was similar to HC. Next, $42 \%$ of $\mathrm{HF}$ patients belonged to the hyper-oxidative (HO) class whose mean GSH/MDA ratio $(0.004787 \pm 0.002055)$ was lower than $\mathrm{HC}$ group $(0.03969 \pm 0.02857)$, and $17 \%$ of $\mathrm{HF}$ patients exhibited a hyper-reductive (HR) state in which mean GSH/MDA ratio $(0.2271 \pm 0.03192)$ was greater than $\mathrm{HC}$ group $(0.03969 \pm 0.02857)$. Interestingly, the GSH/MDA ratios were statistically significant among all three HF groups $(\mathrm{p}<0.0001)$ by one way ANOVA analysis. These novel observations suggest that redox status plays a variable role in the progression of $\mathrm{HF}$ and that both extremes (e.g. oxidative and reductive) may contribute to disease pathogenesis.

\section{Activities of antioxidant enzymes were significantly altered in HF vs. healthy controls}

To assess the capacity of the endogenous antioxidant defense system in the periphery of HF patients, we further analyzed the activity of circulating antioxidant enzymes such as superoxide dismutase (SOD), glutathione reductase (GR), catalase, and glutathione peroxidase (GPx) among the various groups of HF patients (Fig. 2). SOD (Fig. 2a), Gpx (Fig. 2b), catalase (Fig. 2c), GR (Fig. 2d) did not show any statistically significant differences among $\mathrm{NR}, \mathrm{HO}$, and $\mathrm{HR}$ groups of $\mathrm{HF}$ patients. While the activities of SOD $(6.455 \pm 2.30$ for $\mathrm{HO}, 6.646 \pm 2.556$ for $\mathrm{NR}, 6.400 \pm 1.752$ for $\mathrm{HR}$ vs. $2.571 \pm 0.61 \mathrm{U} / \mathrm{ml}$ for $\mathrm{HC}$; Fig. 2a), GPx (527.2 \pm 343.4 for $\mathrm{HO}, 413.3 \pm 243.7$ for $\mathrm{NR}$, $581 \pm 310.2$ for $\mathrm{HR}$ vs. $312 \pm 141.4 \mathrm{U} / \mathrm{l}$ for $\mathrm{HC} ; \mathrm{p}<0.01$; Fig. 2b), and catalase (855.2 \pm 776.5 for $\mathrm{HO}, 787.8 \pm 454.9$ for NR, $1068 \pm 590.3$ for HR vs. $689.1 \pm 556.8 \mathrm{U} / \mathrm{l}$ for $\mathrm{HC}$; $\mathrm{p}<0.05$; Fig. 2c) were significantly increased, GR activity was significantly lower $(11.66 \pm 5.5$ for $\mathrm{HO}, 14.29 \pm 9.86$ for NR, $13.32 \pm 6.79$ for HR vs. $24.70 \pm 28.22 \mathrm{U} / \mathrm{l}$ for $\mathrm{HC}$; $\mathrm{p}<0.05$; Fig. $2 \mathrm{~d}$ ) in all $\mathrm{HF}$ patient groups ( $\mathrm{HO}, \mathrm{NR}$ and HR) relative to healthy controls. 

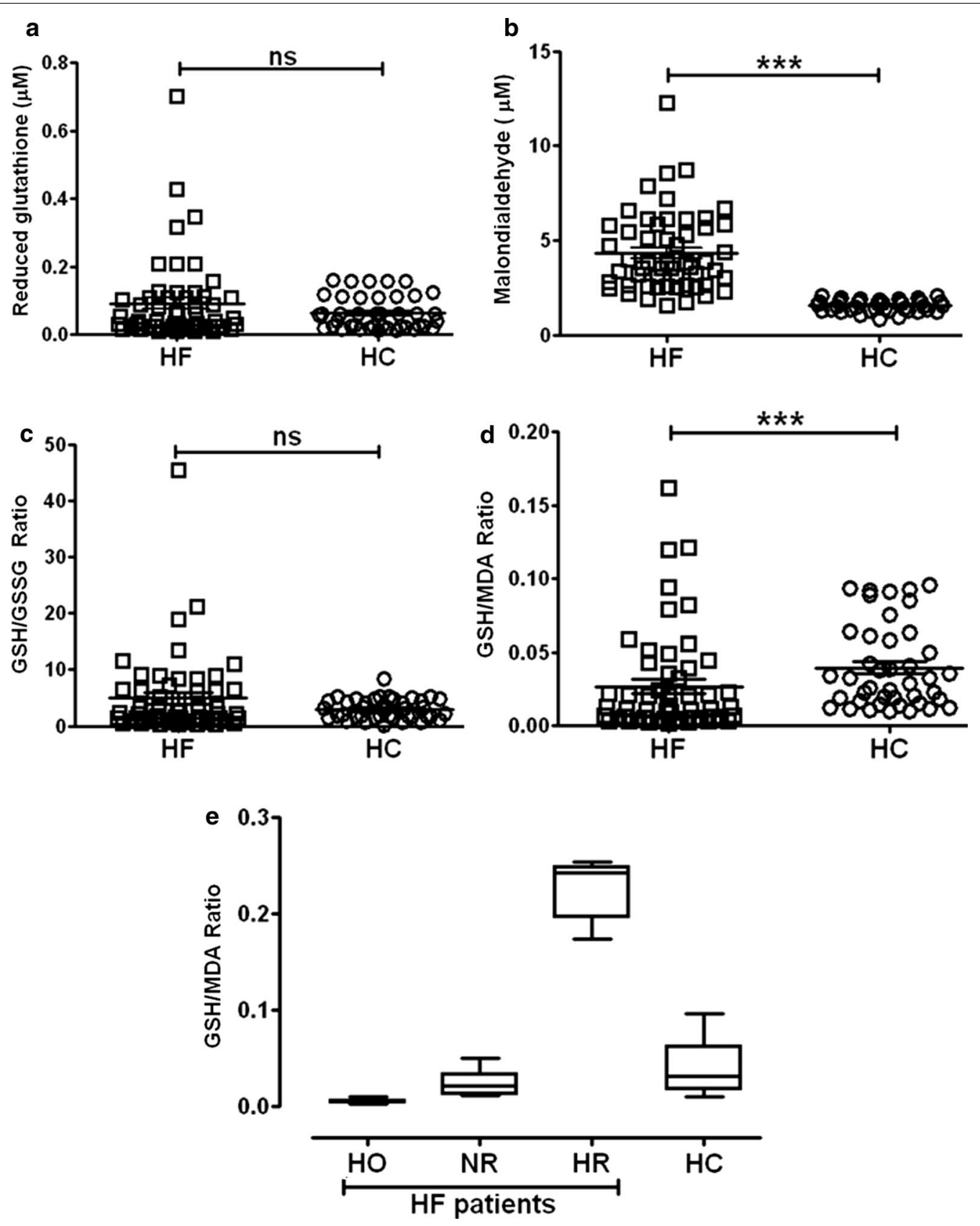

Fig. 1 Stratification of heart failure (HF) patients based on redox status. a Comparison of reduced glutathione (GSH) levels showing statistically insignificant GSH levels between HF patients and HC. b Significantly higher malondialdehyde levels in HF patients vs. HC. c Statistically insignificant GSH/GSSG ratio between HF patients and the healthy controls. d Statistically significant, higher GSH/MDA ratio in HC and lower values in HF patients. Mann-Whitney U test was carried out for statistical significance. ${ }^{* * *} \mathrm{p}<0.001 . \mathrm{n}=42 \mathrm{HC}$ and $54 \mathrm{HF}$ patients. e Stratification of HF patients into hyper-oxidative (HO), normal redox (NR) and hyper-reductive (HR) groups based on comparison of GSH/MDA ratio with healthy controls (HC). Remarkably, higher GSH/MDA ratio in HR group, similar GSH/MDA ratio in NR and HC, and a significantly lower GSH/MDA ratio in HO group were observed. One way ANOVA was carried out with $p<0.0001$ among all the heart failure patient groups $(n=42 \mathrm{HC}, 23 \mathrm{HO}, 22 \mathrm{NR}$, and $9 \mathrm{HR})$

\section{Redox associated changes in cardiac remodeling} and systolic function in HF patients

To relate our biochemical redox observations in the distinct subsets of HF patient with myocardial structural and functional remodeling, we performed non-invasive echocardiography analyses to determine fractional shortening, ejection fraction and left ventricular (LV) mass. First, we confirmed that HF patients 

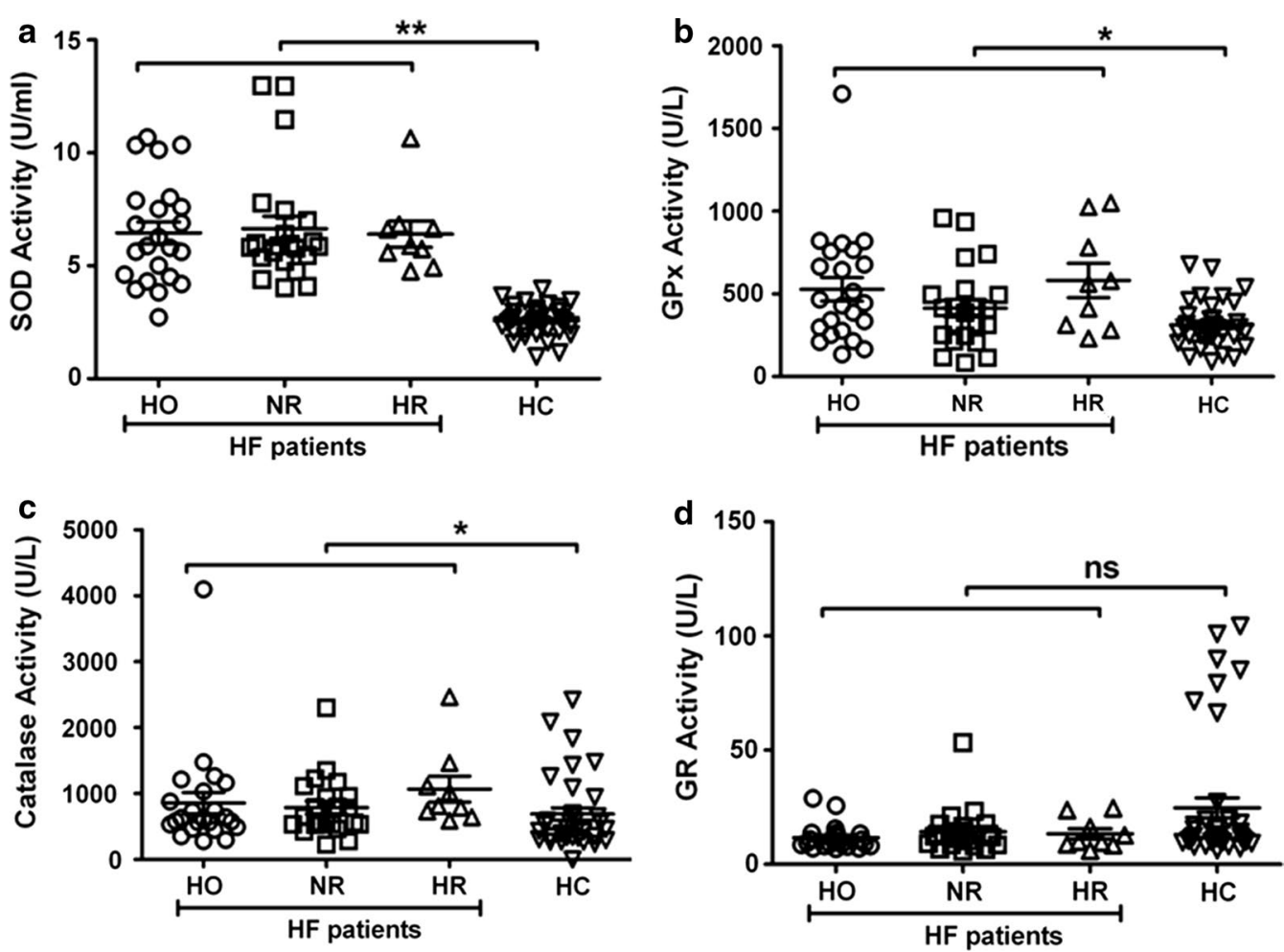

Fig. 2 Comparison of antioxidant enzymes between heart failure (HF) patients and healthy controls. a Statistically significant higher superoxide dismutase activity (SOD) in HF patients compared to healthy controls. b Statistically significant higher glutathione peroxidase activity (GPX) in HF patients compared to healthy controls. c Statistically significant higher catalase activity compared to HC. d Statistically significant lower glutathione reductase activity (GR) compared to HC. One way ANOVA was carried out $\left({ }^{* *} p<0.001,{ }^{*} p<0.05\right)$ among all the heart failure patient groups $(n=, 23$ $\mathrm{HO}, 22 \mathrm{NR}$, and $9 \mathrm{HR} 42 \mathrm{HC}$ except for catalase and GPx, where $\mathrm{n}=35 \mathrm{HC}$ because of limited sample volume)

exhibit significantly distinct myocardial mass and systolic function when compared to HC (Fig. 3a-c). Fractional shortening (Fig. 3a), ejection fraction (Fig. 3b) and LV mass (Fig. 3c) did not show any statistically significant differences among the NR, HO, and HR groups of HF patients. However, when compared with $\mathrm{HC}$, all HF patient groups (HO, NR and HR) showed significantly lower fractional shortening $(17.03 \pm 9.256$ for $\mathrm{HO}, 15.40 \pm 5.863$ for $\mathrm{NR}, 16.54 \pm 5.185$ for $\mathrm{HR}$ vs. $36.13 \pm 6.020$ for $\mathrm{HC} ; \mathrm{p}<0.01)$ and ejection fraction $(33.78 \pm 17.62$ for $\mathrm{HO}, 32.47 \pm 10.41$ for $\mathrm{NR}$, $32.57 \pm 9.424$ for $\mathrm{HR}$ vs. $65.46 \pm 7.9$ for $\mathrm{HC} ; \mathrm{p}<0.01$ ), but significantly greater LV mass $(309.1 \pm 107.9$ for HO, $281.1 \pm 128.2$ for NR, $320.1 \pm 103.8$ for HR vs. $162.6 \pm 13.72$ for $\mathrm{HC}$; $\mathrm{p}<0.01$ ). Representative M-mode echo images for systolic function analysis of NR, HO, HR and healthy control groups are shown in Fig. 3d.

\section{Evidence for a wide range of diastolic abnormalities in HF patients}

Primary measurements of trans-mitral inflow including the peak early filling ( $\mathrm{E}$ wave), late diastolic filling
(A wave) velocities and the E/A ratio were performed in HF patients as well as HC (Fig. $4 \mathrm{a}-\mathrm{C}$ ). Although there was no statistically significant difference between $\mathrm{HF}$ patients and the $\mathrm{HC}$ for ME, MA and ME/A ratio, their measures were widely distributed among the groups compared to the controls (Fig. 4d-f). Representative mitral valve Doppler analysis for diastolic function with graphs for ME/A ratios for HO, NR, HR and healthy control groups are shown in Fig. 4g. M E/A ratio differed according to age and gender [36, 37]. Based on this range, we grouped the HF patients into impaired relaxation and restrictive filling.

Proportion of patients based on systolic (EF) and diastolic (E/A ratio) functions suggest a hyper-reductive condition may be a detrimental factor in HF pathogenesis

Among the HF patients, the HO group (55\%) had a higher percentage of patients with ejection fraction $\leq 30 \%$ than the NR (44.5\%) and HR groups (44.5\%). Patients with an EF between 31 and $40 \%$ were more frequently assigned to the HR group (33.3\%) compared to NR (28\%) and HO groups (18\%). In contrast, HF patients displaying an EF between 41 and 50\% were 

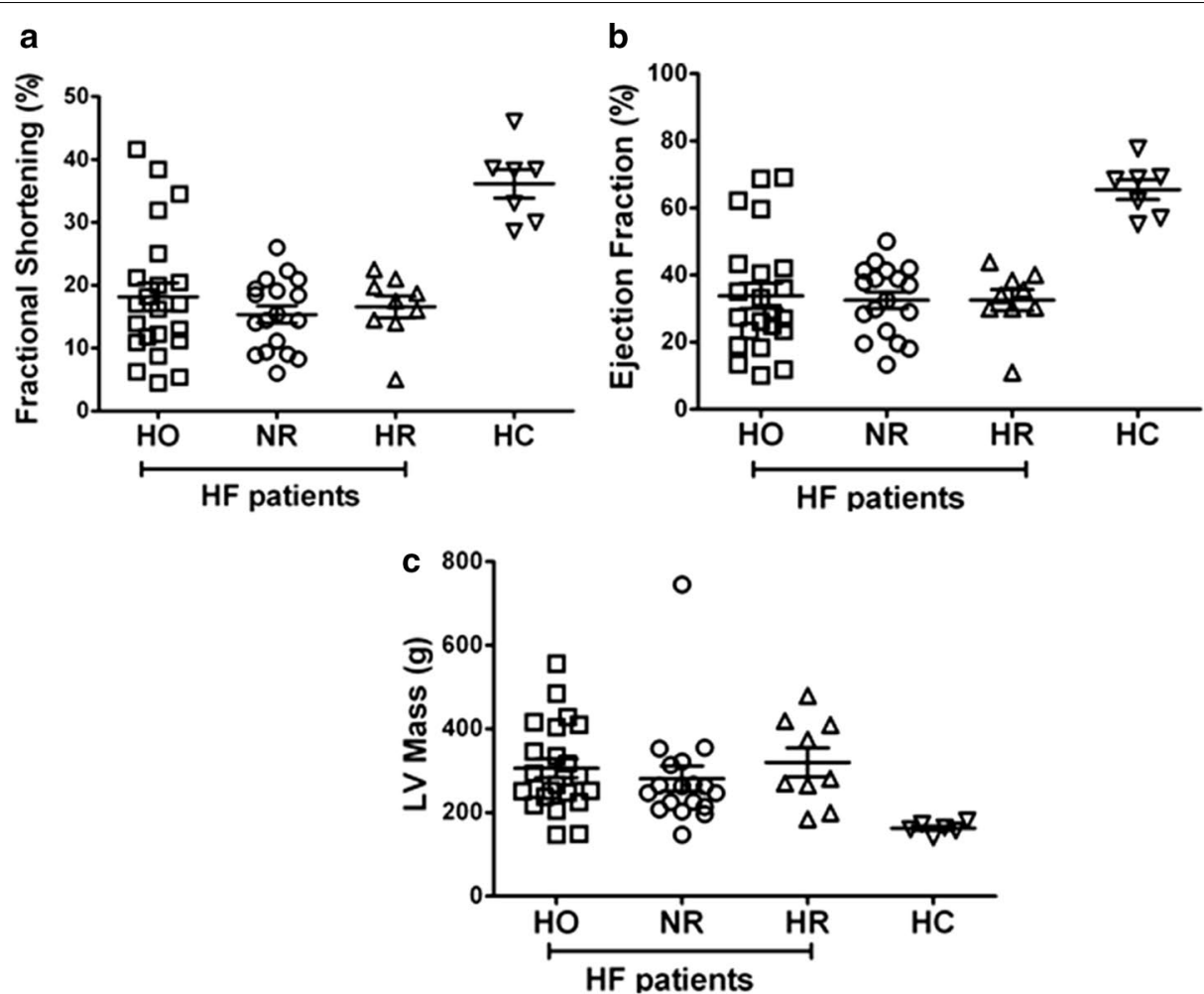

d
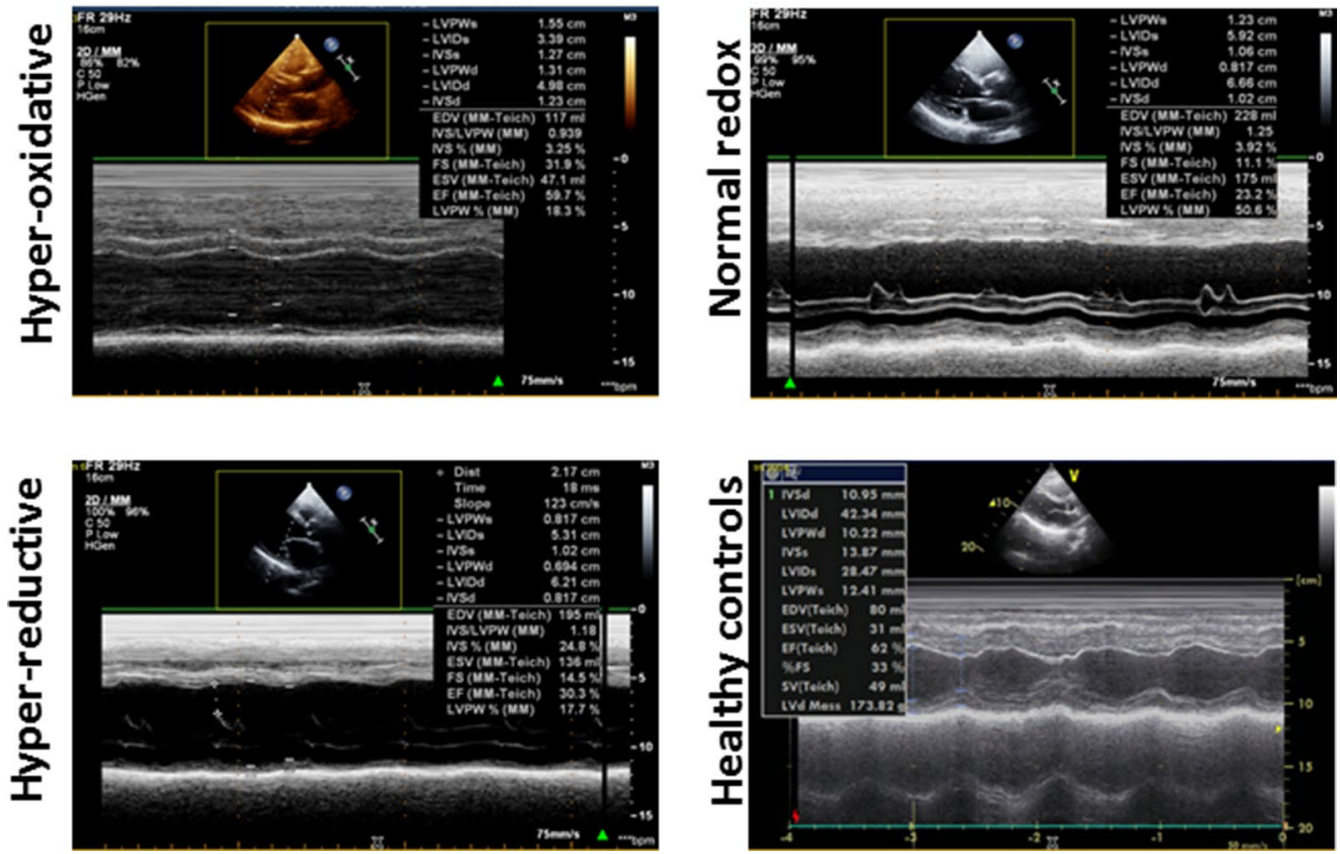

Fig. 3 Echocardiographic parameters for hyper-oxidative (HO), normal redox (NR), hyper-reductive (HR) and healthy controls (HC). a Statistically significant lower percentage of fractional shortening (FS) for HO, NR and HR groups of HF patients compared to HC. b Statistically significant lower percentage of ejection fraction for $\mathrm{HO}, \mathrm{NR}$ and $\mathrm{HR}$ groups of heart failure patients compared to $\mathrm{HC}$ and $\mathbf{c}$ statistically significant higher $\mathrm{LV}$ mass for $\mathrm{HO}$, NR and HR groups of heart failure patients compared to HC. One way ANOVA was carried out with a $p<0.01 \mathrm{vs}$. $\mathrm{HC}$ for $\mathbf{a}-\mathbf{c} n=7 \mathrm{HC}$, $22 \mathrm{HO}, 18 \mathrm{NR}$ and $9 \mathrm{HR}$. M-mode ECHO related parameters focusing on systolic functions and dimensions with ejection fraction (EF) and FS for $\mathbf{d}$ representative $\mathrm{m}$-mode images for each group 

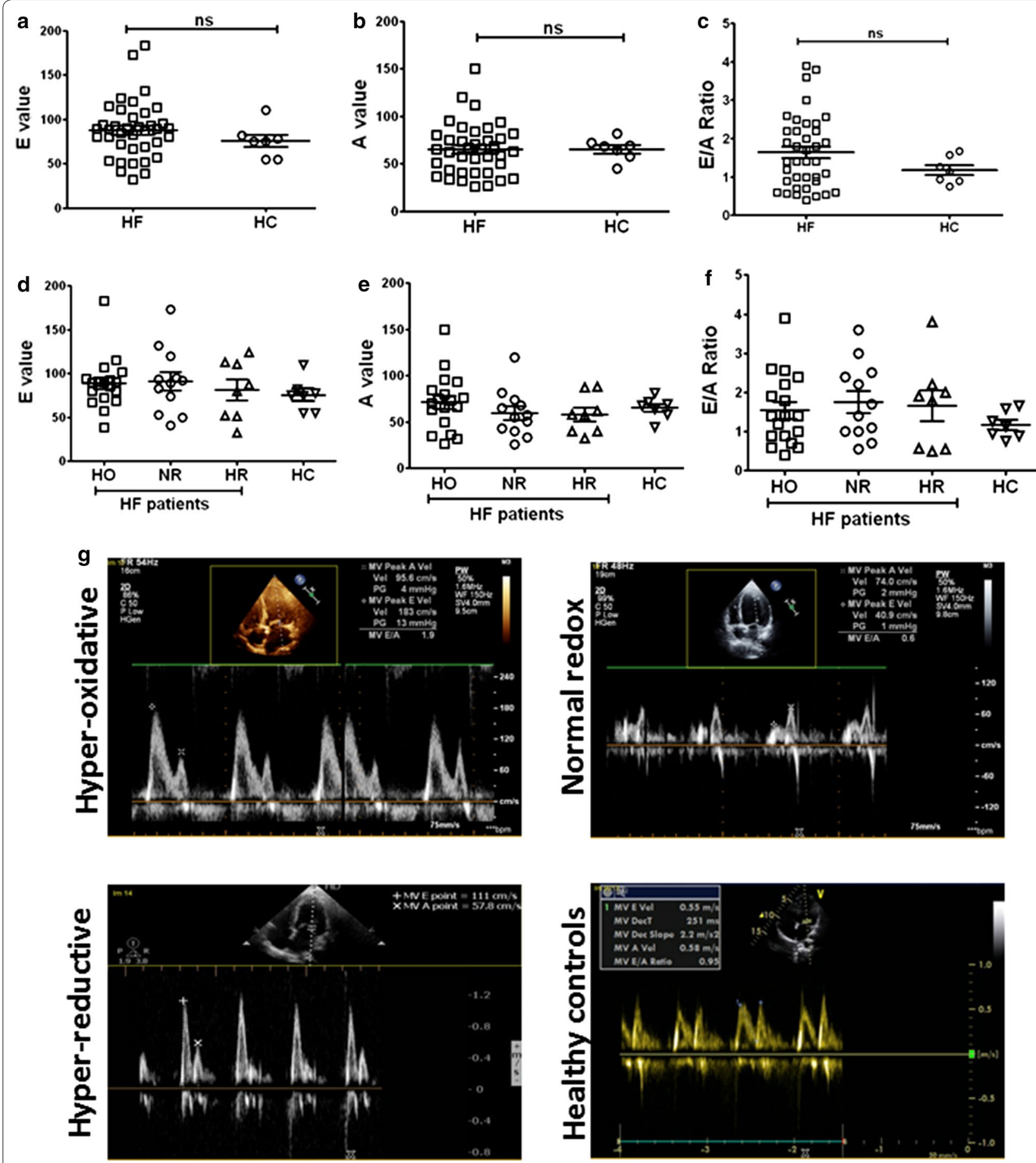

Fig. 4 Comparison of diastolic function abnormalities between HF patients and healthy controls. Similar values between HF patients and healthy controls were observed for $\mathbf{a}$ Early (E) filling, $\mathbf{b}$ late (A) filling and $\mathbf{c}$ E/A ratio. Mann-Whitney $U$ test was carried out with no statistical significance among the groups for $\mathbf{a}-\mathbf{c}, \mathrm{n}=7 \mathrm{HC}$ and $38 \mathrm{HF}$ patients. $\mathbf{d}$ Early (E) filling values were slightly higher in $\mathrm{HF}$ group patients (HO, NR and HR) than healthy controls. Relative to healthy controls, e late (A) filling values and were slightly higher in $\mathrm{HO}$ and lower in NR and $\mathrm{HR}$. f E/A ratio were slightly higher in $\mathrm{HF}$ group patients ( $\mathrm{HO}, \mathrm{NR}$ and HR) than healthy controls. $n=7 \mathrm{HC}, 18 \mathrm{HO}, 12 \mathrm{NR}$ and $8 \mathrm{HR}$. One way ANOVA was carried out with no statistical significance among the groups for $\mathbf{d}-\mathbf{f}$. Mitral valve Doppler analysis for diastolic function with graphs for M E/A ratios for $\mathbf{g}$. Representative mitral valve Doppler images for each group 
less prone to be classified as $\mathrm{HO}(9 \%)$ when compared to the NR (22\%) and HR groups (22\%). Intriguingly, HF patients with HFpEF were completely absent in HR groups relative to $\mathrm{HO}(18 \%)$ and NR patients $(5.5 \%)$ (Fig. 5a).

Using the ME/A ratio as an index, diastolic function was compared between different HF groups and healthy controls (Fig. 5b). To our surprise, none of the HR patients exhibited normal diastolic function (E/A ratio $0.76-1.6)$; however, $41.3 \%$ of $\mathrm{HO}$ and $33 \%$ of NR patients revealed such E/A ratios. While only $17 \%$ of NR patients exhibited impaired relaxation ( $\mathrm{E} / \mathrm{A}$ ratio $\leq 0.75)$, the incidence of impaired relaxation in $\mathrm{HR}$ and $\mathrm{HO}$ patients were 37.5 and $23.5 \%$ respectively. Finally, the HR group had higher percentage of patients $(62.5 \%)$ with restrictive filling $(\mathrm{E} / \mathrm{A}$ ratio $\geq 1.61)$ as compared with $\mathrm{HO}(35.2 \%)$ and NR patients (50\%). Fisher's exact test was carried out with no statistical significance for EF fraction and E/A ratio among the $\mathrm{HO}, \mathrm{NR}$, and $\mathrm{HR}$ group of HF patients.

\section{Discussion}

The current understanding of redox changes during heart failure (HF) is centered on results obtained from a given group of HF patients compared to healthy controls. Importantly, this experimental approach assumes that redox imbalances during HF progression conform to the oxidative stress paradigm and neglect the potential for observations of individual redox responses in unique subsets of cardiac patients. Here, we attempted to investigate the individual differences of circulating redox biomarkers such as reduced glutathione (GSH), its redox ratio (GSH/GSSG), lipid peroxidation levels (i.e. MDA) and its normalization to reduced glutathione (i.e. GSH/ MDA). In particular, we examined whether some HF patients exhibit a unique redox state that is likely to be stretched on either direction of the redox spectrum (i.e. hyper-reductive vs. hyper-oxidative). The development of HF might occur in response to various factors including a chronic oxidative stress/inflammation, infection, ischemic insult, genetic cues and other chronic stresses [38, 39]. Hither to, the redox-based classification of HF has not been implemented.

Generation of reactive oxygen/nitrogen species (ROS/ RNS) and oxidative stress has been reported to be associated with the development of HF [40, 41]. However, the evidence for oxidative stress as a causal factor for chronic $\mathrm{HF}$ is ambiguous as oxidative stress is absent at the onset of HF in some patients while it appears as a consequence at the later stages of the disease in others. Therefore, we postulate that the oxidative stress may not be solely responsible for the development of $\mathrm{HF}$, and that the other extreme of the redox continuum, reductive stress (RS; a

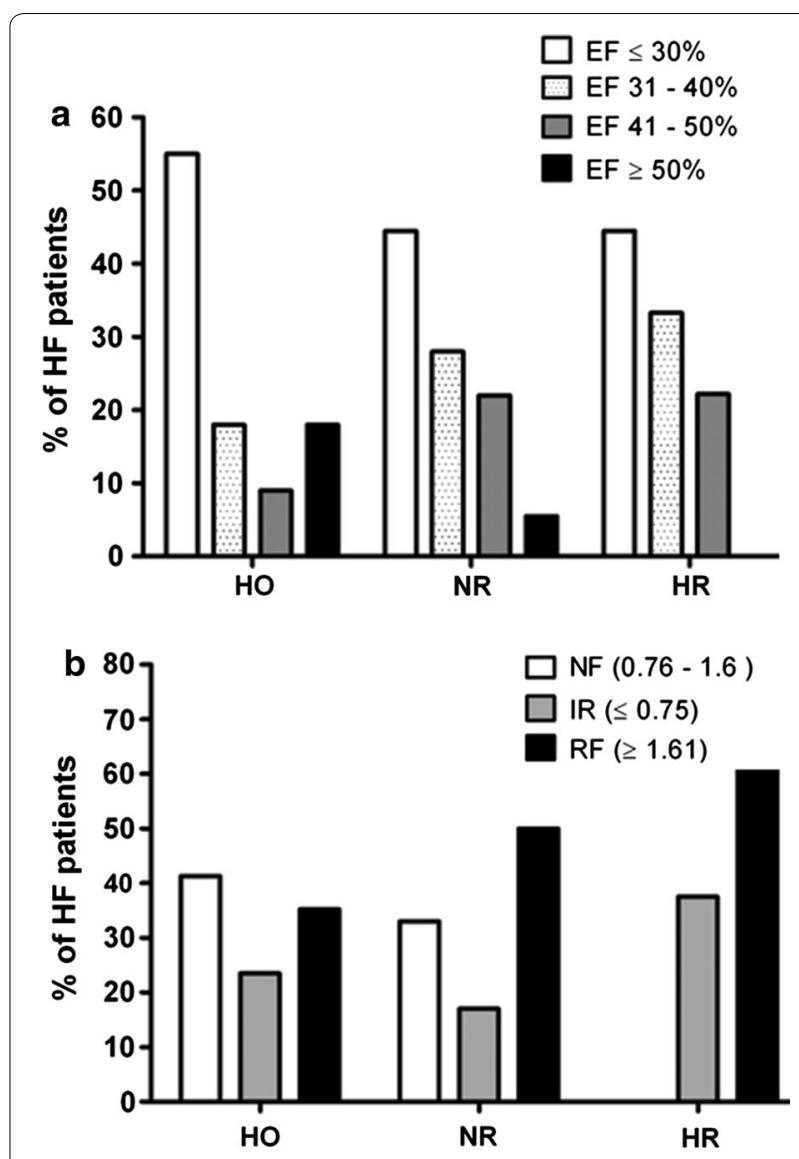

Fig. 5 Comparison of systolic functions (EF) and diastolic functions (E/A ratio) among hyper-oxidative, normal redox and hyper-reductive groups of HF patients. a Comparison of ejection fraction (EF) among hyper-oxidative $(\mathrm{HO})$, normal redox (NR) and hyper-reductive (HR) groups of $\mathrm{HF}$ patients indicating higher number of $\mathrm{HO}$ patients have lowest range of $\mathrm{EF} \leq 30 \%$ and patients with highest range of $\mathrm{EF} \geq 50 \%$ are absent in HR group. $\mathbf{b}$ Comparison of E/A ratio among $\mathrm{HO}, \mathrm{NR}$ and $\mathrm{HR}$ groups of cardiac failure patients with normal filling (NF), impaired relaxation (IR) and restrictive filling (RF) indicating that the HR group had higher number of patients with RF and $\mathrm{HO}$ group had higher patients with NF. Fisher's exact test was carried out with no statistical significance for EF fraction and E/A ratio among the $\mathrm{HO}$, NR, HR group of HF patients

hyper-reductive condition) may play an equally pathological role in certain instances. In the past decade, we and others have suggested that RS might also be an additional mechanism that causes pathological cardiac remodeling leading to heart failure [30, 42-44]. Notably, the existence of RS as a key driver of pathogenesis has been shown in a human mutant protein aggregation cardiomyopathy with augmented antioxidant capacity [30, 45]. Furthermore, other laboratories have reported that augmentation of HSP25, a molecular chaperone that co-regulates glutathione metabolism, promoted RS and resulted in cardiac hypertrophy in transgenic mice expressing Hsp25 
[44]. Of late, it has been shown that significant upregulation of NADPH in the heart promotes reductive stress and exacerbates myocardial injury in a mouse model [46]. Nonetheless, such an evidence for RS or a hyperreductive condition in human HF has not been demonstrated. Our current observations in a small cohort of HF patients $(n=54)$ have indicated that a distinct subset of HF patients exhibit a hyper-reductive condition in their circulation. Thus, we believe that our novel findings might be useful in stratifying HF patients based on the circulatory redox state (CRS) and in designing appropriate treatment strategies targeting antioxidants.

Based on the CRS (i.e. GSH/MDA), HF patients were stratified into three distinct groups, namely HF patients with (a) hyper-oxidative (HO), (b) normal redox (NR), and (c) hyper-reductive (HR) conditions. Interestingly, while a majority of the HF patients fall into the $\mathrm{HO}(42 \%)$ and NR (41\%) categories, a small subset exhibited the HR $(n=17 \%)$. Of note, these observations suggest that not all HF patients experience oxidative stress. Therefore, a key question remains as to how and why NR or HR redox conditions contribute to the development of HF remains. Although these analyses seem to be novel and interesting, the mechanisms for NR and/or HR redox conditions in the development of HF are yet to be discovered. Importantly, changes in circulating redox biomarkers in a single group of HF patients appear to be insignificant when compared to healthy controls as the individual levels of CRS have a wide range, which masks the actual scenario in a given HF patient. Hence, our approach for stratifying HF patients based on their CRS will be appropriate to gain more knowledge and understand the pathogenesis of HF in a personalized manner that is likely to enhance the potential of a patient's treatment. Furthermore, we believe that a basic and simple biochemical clinical test for the CRS of a HF patient is a feasible strategy to improve the patient's health and increase their survival through selecting appropriate treatment strategies.

In the majority of the patients ( $>85 \%$ ), our CRS measurements were performed upon the first hospital admission. Critically, we meticulously confirmed that none of the subjects had consumed antioxidant supplements prior to this visit, thereby indicating a clear picture of a hyper-reductive condition associated with HF. In addition to providing the first evidence for an abnormally reductive state in human HF patients, another key finding of our study is the wide heterogeneity of the CRS in response to HF. Along these lines, the prevalence of NR and $H R$ in a considerable number of participants contradicts the expected HO. Considering that ROS/RNS serve as key cellular signaling molecules for basal physiology and responses/adaptations to acute/chronic stress conditions [47-49], patients who exhibit NR or HR may have not gained protection from developing HF. Altogether, these results indicate that in contrast to the common understanding, oxidative stress is not the only factor inducing HF.

Next, our detailed analyses of cardiac structure and function among the 3 classes of HF patients revealed interesting information. Although there is no statistically significant differences among the groups, most of the HO patients displayed severe systolic dysfunction with an ejection fraction $\leq 30 \%$ when compared with NR and HR group. It has been established that an over production of ROS/RNS adversely alters cardiac function eventually leading to diastolic and systolic dysfunction [50, 51]. Moreover, left ventricular (LV) dysfunction in HF patients correlates well with the extent of oxidative stress in the myocardium and plasma [50]. In the HR group none of the patients had HFpEF and only $5 \%$ in NR group. Hence, both the HR and NR groups predominantly have mild to moderate systolic dysfunction. As such, we speculate that oxidative stress could be a major cause for severe systolic dysfunction rather than reductive stress. In addition to systolic function, we assessed the grade of diastolic dysfunction among the three groups of HF patients utilizing noninvasive Doppler echocardiography mitral inflow (E/A ratio). Surprisingly, the HR group exhibited a higher percentage of patients with a restrictive filling pattern while none for normal filling pattern. However, all other groups had almost equal percentage of patients with normal filling pattern. From our data, it is apparent that patients with RS have severe diastolic dysfunction as compared with normal redox and oxidative stress conditions. Specifically, reductive stress imparts both mild to moderate systolic dysfunction and severe diastolic dysfunction among HF patient groups. There has been accumulating evidence indicating that HF with systolic dysfunction is associated with oxidative stress and nitric oxide (NO) signaling [52] whereas our observations suggest a novel role for reductive stress in the development of diastolic dysfunction.

\section{Conclusion}

In this study, we believe that we provided evidence supporting the presence of a hyper-reductive (i.e. reductive stress) condition in a subset of HF patients. Notably, we observed that the HR-HF group had a higher percentage of patients with diastolic dysfunction while the HO-HF group exhibited a higher percentage of patients with systolic dysfunction. Further, individual differences in CRS during the development of HF are apparent suggesting unique contributions of redox disequilibrium across distinct classes of patients. The exact nature of the mechanisms responsible for the heterogeneity in redox responses in the context of HF is presently unknown. We 
consider that the wide inter-individual variability for CRS shown here is not limited to the two biomarkers (GSH and MDA) of the redox milieu. Remarkably, the data presented herein emphasize that the mean CRS of a group of HF patients can be misleading. We also acknowledge that this pilot study included a small (but tightly controlled for age and other comorbidities) and male dominant cohort of HF patients. Therefore, our future investigations will focus on larger groups including both genders with specific types of HF such as ischemic disease, hypertrophic cardiomyopathy, dilated cardiomyopathy, and rheumatoid cardiac diseases, and will accentuate differences in diastolic vs. systolic dysfunctions.

\section{Authors' contributions}

TS and NSR conceived the idea, performed the experiments and wrote the manuscript. MS performed experiments and collected data. RG, SR and SR provided samples, resources and processed ethical approvals. ANP and SMP critically reviewed and revised the clinical portion of the results. All authors read and approved the final manuscript.

\section{Author details \\ ${ }^{1}$ Cardiac Aging \& Redox Signaling Laboratory, Center for Free Radical Biology, Division of Molecular \& Cellular Pathology, Department of Pathology, UAB|The University of Alabama at Birmingham, BMR2 Room 533|901 19th Street South, Birmingham, AL 35294-2180, USA. ${ }^{2}$ PSG Center for Molecular Medicine and Therapeutics, PSG Institute of Medical Sciences \& Research (Affiliated to the Tamilnadu Dr MGR Medical University), Coimbatore, Tamil Nadu, India. \\ ${ }^{3}$ Division of Cardiothoracic Surgery, University of Miami-Miller School of Medi- cine, Miami, FL, USA. ${ }^{4}$ Department of Cardiology, PSG Institute of Medical Sciences \& Research (Affiliated to the Tamilnadu Dr MGR Medical University), Coimbatore, Tamil Nadu, India. ${ }^{5}$ Comprehensive Cardiovascular Center, Department of Medicine, University of Alabama at Birmingham, Birmingham, AL, USA. ${ }^{6}$ Cardiovascular Medicine, University of Utah School of Medicine, Salt Lake City, UT, USA.}

\section{Acknowledgements}

The authors greatly thank Dr. Gobinath Shanmugam for assisting with the data analysis and Figures. Also appreciate Dr. Anil Challa and Mr. Justin Quiles for preview and editorial assistance and Dr. Merlin Veronika for statistical assistance

\section{Competing interests}

The authors declare that they have no competing interests.

\section{Availability of data and materials}

The datasets used and/or analyzed during the current study are available from the corresponding authors on reasonable request.

\section{Consent for publication}

Written consent for publication was obtained from the patients.

\section{Ethics approval and consent to participate}

The study was approved by the PSG Institutional Human Ethics Committee (IHEC) and all patients/subjects completed a written informed consent prior to their participation.

\section{Funding}

This study was supported by funding from PSG Center for Molecular Medicine and Therapeutics, PSG Institute of Medical Sciences \& Research (for SR), Coimbatore, Tamil Nadu, India and Department of Pathology/School of Medicine start-up funds (for NSR Travel) University of Alabama at Birmingham, AL.

\section{Publisher's Note}

Springer Nature remains neutral with regard to jurisdictional claims in published maps and institutional affiliations.

Received: 19 February 2018 Accepted: 3 May 2018

Published online: 18 May 2018

\section{References}

1. Elahi MM, Kong YX, Matata BM. Oxidative stress as a mediator of cardiovascular disease. Oxid Med Cell Longev. 2009;2:259-69.

2. Tsutsui $H$, Kinugawa $S$, Matsushima S. Oxidative stress and heart failure. Am J Physiol Heart Circ Physiol. 2011;301:H2181-90.

3. Blomhoff R. Dietary antioxidants and cardiovascular disease. Curr Opin Lipidol. 2005;16:47-54.

4. Gotto AM. Antioxidants, statins, and atherosclerosis. J Am Coll Cardiol. 2003;41:1205-10.

5. Ben-Haim S, Gacinovic S, Israel O. Cardiovascular infection and inflammation. Semin Nucl Med. 2009;39:103-14.

6. Gorski PA, Ceholski DK, Hajjar RJ. Altered myocardial calcium cycling and energetics in heart failure-a rational approach for disease treatment. Cell Metab. 2015;21:183-94.

7. Van Linthout S, Tschope C. Inflammation-cause or consequence of heart failure or both? Curr Heart Fail Rep. 2017;14:251-65.

8. Zhou Q, Zhao C, Xie D, Xu D, Bin J, Chen P, Liang M, Zhang X, Hou F. Acute and acute-on-chronic kidney injury of patients with decompensated heart failure: impact on outcomes. BMC Nephrol. 2012;13:51.

9. Bagheri F, Khori V, Alizadeh AM, Khalighfard S, Khodayari S, Khodayari H. Reactive oxygen species-mediated cardiac-reperfusion injury: mechanisms and therapies. Life Sci. 2016;165:43-55.

10. Bilenko MV, Vladimirov luA, Pavlova SA, Thu Thuy NT, Hai Yen TT. Production of reactive oxygen species by monocyte-derived macrophages from the blood of healthy donors and patients with IHD. Biomed Khim. 2008;54:445-53.

11. Ellidag HY, Eren E, Yilmaz N, Cekin Y. Oxidative stress and ischemiamodified albumin in chronic ischemic heart failure. Redox Rep. 2014;19:118-23.

12. Kritharides $L$, Stocker R. The use of antioxidant supplements in coronary heart disease. Atherosclerosis. 2002;164:211-9.

13. Saremi A, Arora R. Vitamin E and cardiovascular disease. Am J Ther. 2010;17:e56-65.

14. Tornwall ME, Virtamo J, Korhonen PA, Virtanen MJ, Taylor PR, Albanes D, Huttunen JK. Effect of alpha-tocopherol and beta-carotene supplementation on coronary heart disease during the 6-year post-trial follow-up in the ATBC study. Eur Heart J. 2004;25:1171-8.

15. Akhlaghi M, Bandy B. Mechanisms of flavonoid protection against myocardial ischemia-reperfusion injury. J Mol Cell Cardiol. 2009;46:309-17.

16. Breitbart E, Lomnitski L, Nyska A, Malik Z, Bergman M, Sofer Y, Haseman JK, Grossman S. Effects of water-soluble antioxidant from spinach, NAO, on doxorubicin-induced heart injury. Hum Exp Toxicol. 2001;20:337-45.

17. Qin CX, Williams SJ, Woodman OL. Antioxidant activity contributes to flavonol cardioprotection during reperfusion of rat hearts. Free Radical Biol Med. 2011;51:1437-44.

18. Briancon S, Boini S, Bertrais S, Guillemin F, Galan P, Hercberg S. Long-term antioxidant supplementation has no effect on health-related quality of life: the randomized, double-blind, placebo-controlled, primary prevention SU.VI.MAX trial. Int J Epidemiol. 2011;40:1605-16.

19. Tribble DL. AHA Science Advisory. Antioxidant consumption and risk of coronary heart disease: emphasis on vitamin C, vitamin E, and betacarotene: a statement for healthcare professionals from the American Heart Association. Circulation. 1999;99:591-5.

20. Vivekananthan DP, Penn MS, Sapp SK, Hsu A, Topol EJ. Use of antioxidant vitamins for the prevention of cardiovascular disease: meta-analysis of randomised trials. Lancet. 2003;361:2017-23.

21. Hare JM, Stamler JS. NO/redox disequilibrium in the failing heart and cardiovascular system. J Clin Invest. 2005;115:509-17.

22. Pagliaro P, Penna C. Redox signalling and cardioprotection: translatability and mechanism. Br J Pharmacol. 2015:172:1974-95. 
23. Sugamura K, Keaney JF Jr. Reactive oxygen species in cardiovascular disease. Free Radic Biol Med. 2011;51:978-92.

24. Valko M, Leibfritz D, Moncol J, Cronin MT, Mazur M, Telser J. Free radicals and antioxidants in normal physiological functions and human disease. Int J Biochem Cell Biol. 2007;39:44-84.

25. King M, Kingery J, Casey B. Diagnosis and evaluation of heart failure. Am Fam Physician. 2012;85:1161-8.

26. Lang RM, Badano LP, Mor-Avi V, Afilalo J, Armstrong A, Ernande L, Flachskampf FA, Foster E, Goldstein SA, Kuznetsova T, et al. Recommendations for cardiac chamber quantification by echocardiography in adults: an update from the American Society of Echocardiography and the European Association of Cardiovascular Imaging. Eur Heart J Cardiovasc Imaging. 2015;16:233-70.

27. Wilson DJ, North $\mathrm{N}$, Wilson RA. Comparison of left ventricular ejection fraction calculation methods. Echocardiography. 1998;15:709-12.

28. Rezaei Z, Jamshidzadeh A, Sanati E. A rapid and sensitive method for the determination of malondialdehyde as its hydralazine derivative in human plasma using high performance liquid chromatography. Anal Methods. 2013;5:2995-9.

29. Rahman I, Kode A, Biswas SK. Assay for quantitative determination of glutathione and glutathione disulfide levels using enzymatic recycling method. Nat Protoc. 2006;1:3159-65.

30. Rajasekaran NS, Connell P, Christians ES, Yan LJ, Taylor RP, Orosz A, Zhang XQ, Stevenson TJ, Peshock RM, Leopold JA, et al. Human alpha B-crystallin mutation causes oxido-reductive stress and protein aggregation cardiomyopathy in mice. Cell. 2007;130:427-39.

31. Martensson J, Meister A. Glutathione deficiency increases hepatic ascorbic acid synthesis in adult mice. Proc Natl Acad Sci USA. 1992;89:11566-8.

32. Javed M, Ahmad MI, Usmani N, Ahmad M. Multiple biomarker responses (serum biochemistry, oxidative stress, genotoxicity and histopathology) in Channa punctatus exposed to heavy metal loaded waste water. Sci Rep. 2017;7:1675

33. Shangari N, O'Brien PJ. Catalase activity assays. Curr Protoc Toxicol. 2006 https://doi.org/10.1002/0471140856.tx0707s27.

34. Frasier CR, Sloan RC, Bostian PA, Gonzon MD, Kurowicki J, Lopresto SJ, Anderson EJ, Brown DA. Short-term exercise preserves myocardial glutathione and decreases arrhythmias after thiol oxidation and ischemia in isolated rat hearts. J Appl Physiol. 1985:2011(111):1751-9.

35. Noeman SA, Hamooda HE, Baalash AA. Biochemical study of oxidative stress markers in the liver, kidney and heart of high fat diet induced obesity in rats. Diabetol Metab Syndr. 2011;3:17.

36. Nagueh SF, Smiseth OA, Appleton CP, Byrd BF 3rd, Dokainish H, Edvardsen T, Flachskampf FA, Gillebert TC, Klein AL, Lancellotti P, et al. Recommendations for the evaluation of left ventricular diastolic function by echocardiography: an update from the American society of echocardiography and the European association of cardiovascular imaging. Eur Heart J Cardiovasc Imaging. 2016;17:1321-60.

37. Nagueh SF, Smiseth OA, Appleton CP, Byrd BF 3rd, Dokainish H, Edvardsen T, Flachskampf FA, Gillebert TC, Klein AL, Lancellotti P, et al. Recommendations for the evaluation of left ventricular diastolic function by echocardiography: an update from the American society of echocardiography and the European association of cardiovascular imaging. J Am Soc Echocardiogr. 2016;29:277-314.
38. Machado FS, Tanowitz HB, Ribeiro AL. Pathogenesis of chagas cardiomyopathy: role of inflammation and oxidative stress. J Am Heart Assoc. 2013:2:e000539.

39. Ribeiro-Samora GA, Rabelo LA, Ferreira ACC, Favero M, Guedes GS, Pereira LSM, Parreira VF, Britto RR. Inflammation and oxidative stress in heart failure: effects of exercise intensity and duration. Braz J Med Biol Res. 2017;50:e6393.

40. Moris D, Spartalis M, Spartalis E, Karachaliou GS, Karaolanis GI, Tsourouflis $\mathrm{G}$, Tsilimigras DI, Tzatzaki E, Theocharis $\mathrm{S}$. The role of reactive oxygen species in the pathophysiology of cardiovascular diseases and the clinical significance of myocardial redox. Ann Transl Med. 2017:5:326.

41. Moris D, Spartalis M, Tzatzaki E, Spartalis E, Karachaliou GS, Triantafyllis AS, Karaolanis GI, Tsilimigras DI, Theocharis S. The role of reactive oxygen species in myocardial redox signaling and regulation. Ann Transl Med. 2017;5:324

42. Brewer AC, Mustafi SB, Murray TV, Rajasekaran NS, Benjamin IJ. Reductive stress linked to small HSPs, G6PD, and Nrf2 pathways in heart disease. Antioxid Redox Signal. 2013;18:1114-27.

43. Kannan S, Muthusamy VR, Whitehead KJ, Wang L, Gomes AV, Litwin SE, Kensler TW, Abel ED, Hoidal JR, Rajasekaran NS. Nrf2 deficiency prevents reductive stress-induced hypertrophic cardiomyopathy. Cardiovasc Res. 2013;100:63-73.

44. Zhang X, Min X, Li C, Benjamin IJ, Qian B, Zhang X, Ding Z, Gao X, Yao $Y, M a Y$, et al. Involvement of reductive stress in the cardiomyopathy in transgenic mice with cardiac-specific overexpression of heat shock protein 27. Hypertension. 2010;55:1412-7.

45. Rajasekaran NS, Varadharaj S, Khanderao GD, Davidson CJ, Kannan S, Firpo MA, Zweier JL, Benjamin IJ. Sustained activation of nuclear erythroid 2-related factor 2 /antioxidant response element signaling promotes reductive stress in the human mutant protein aggregation cardiomyopathy in mice. Antioxid Redox Signal. 2011;14:957-71.

46. Yu Q, Lee CF, Wang W, Karamanlidis G, Kuroda J, Matsushima S, Sadoshima J, Tian R. Elimination of NADPH oxidase activity promotes reductive stress and sensitizes the heart to ischemic injury. J Am Heart Assoc. 2014;3:e000555.

47. Afanas'ev I. ROS and RNS signaling in heart disorders: could antioxidant treatment be successful? Oxid Med Cell Longev. 2011;2011:293769.

48. Phaniendra A, Jestadi DB, Periyasamy L. Free radicals: properties, sources, targets, and their implication in various diseases. Indian J Clin Biochem. 2015;30:11-26.

49. Yan $\sqcup$. Positive oxidative stress in aging and aging-related disease tolerance. Redox Biol. 2014:2:165-9.

50. Munzel T, Camici GG, Maack C, Bonetti NR, Fuster V, Kovacic JC. Impact of oxidative stress on the heart and vasculature: part 2 of a 3-part series. J Am Coll Cardiol. 2017;70:212-29.

51. Munzel T, Gori T, Keaney JF Jr, Maack C, Daiber A. Pathophysiological role of oxidative stress in systolic and diastolic heart failure and its therapeutic implications. Eur Heart J. 2015;36:2555-64

52. Jeong EM, Dudley SC Jr. Diastolic dysfunction. Circ J. 2015;79:470-7.
Ready to submit your research? Choose BMC and benefit from:

- fast, convenient online submission

- thorough peer review by experienced researchers in your field

- rapid publication on acceptance

- support for research data, including large and complex data types

- gold Open Access which fosters wider collaboration and increased citations

- maximum visibility for your research: over 100M website views per year

At BMC, research is always in progress.

Learn more biomedcentral.com/submissions 